\title{
Testing and Refining a Neonatal Resuscitation Training Model for Semi-Skilled Birth Attendants to Manage Neonatal Emergencies in Oyo State, Nigeria.
}

Adenike Olaniyi ( $\square$ adenikeolaniyi4@gmail.com ) University of KwaZulu-Natal College of Health Sciences https://orcid.org/0000-0002-1919-0567

\section{Busisiwe Ncama}

University of KwaZulu-Natal College of Health Sciences

\section{Research article}

Keywords: Neonatal, Testing, Refining, Community Health Worker, Hypoxia

Posted Date: October 22nd, 2019

DOI: https://doi.org/10.21203/rs.2.16350/v1

License: (c) (i) This work is licensed under a Creative Commons Attribution 4.0 International License. Read Full License 


\section{Abstract}

Background: Helping Babies Breathe (HBB) is a stimulated-based educational model developed to training birth attendants in low-income counties in basic neonatal stabilization. The scientific basis of HBB stemmed from neonatal evidence evaluation. Evaluation of this model gives an exhaustive understanding of the effectiveness of the training process and potential needs for improvement. Methods: This was a mixed method study conducted to test an existing, and develop an acceptable model suitable for the training of semi-skilled birth attendants in rural Nigeria. Data intake was both quantitative and qualitative using sequential approach. Questionnaire was used for quantitative data collection, while focus group discussions and individual in-depth interviews were adopted for qualitative. Qualitative data was entered into SPSS version 21, qualitative data were digitally recorded and transcribed. Both sets of data was coded and analyzed. Result: Findings from this study revealed very poor knowledge and skills of neonatal resuscitation among semi-skilled birth attendants before training was instituted. Their knowledge and resuscitative skills improved immediately after the training. The adapted model was evaluated and refined to suit the training of semi-skilled birth attendants in rural Nigeria. The outcomes were impressive, almost all respondents had improved skills in both newborn care and resuscitation of asphyxiated newborns. Conclusion: This refined model of training of semi-skilled birth attendants will improve neonatal care through advancement of educational efficacy. This model of training should be implemented by relevant stakeholders in the care of children to reduce newborn mortality and improve survival. Keywords: Neonatal, Testing, Refining, Community Health Worker, Hypoxia

\section{Background}

The evaluation of feasibility and accessibility of a training tool is an essential feature of quality control in training in order to ensure that the strength and energy put in during the training were worthwhile. In determining the suitability of the content of the training modules for the achievement of desired skills and knowledge, it is relevant to determine the appropriateness of the training and target participant. Appraisals of innovative opportunities for learning and collaboration are needed if extensive knowledge translation, especially in rural areas, is to be accomplished ${ }^{1}$. According to $\mathrm{WHO}$, health promotion is a procedure of empowering people to intensify and manage influencing factors of health, thus improving their health ${ }^{2}$. It can be described as a series of actions directed to training people to handle health determinants and make decision that contribute to positive behaviour and outcomes. It can be defined as an established proficiency and ability which includes assimilating, understanding, personal view, and practices from various experts which are required to reduce the influence that social determinants can have on individual health status $^{3}$. This description is founded on 1986 WHO Charter in Ottawa ${ }^{4}$ and Declaration in Jakarta based on leading health promotion into the $21^{\text {st }}$ century, $1997^{5}$ that form the general principles, which guide health promotion practice. In this framework of health promotion, hospitals can function as prospective establishments that encourage health and well-being between professionals and health care consumers. Also, hospitals that encourage health ensure quality care, and embrace policies for training professionals, patients, and families with the aim of causing them effective and involved in the taking responsibility of their well-being (Barry et al.). It is therefore, ultimate to form a team that is capable of instituting and utilizing health promotion in their settings, together with professional education to acquire competencies ${ }^{6}$. Competencies are described as utilizing distinctive knowledge and expert skills to carrying out standard of an action necessary in an exact context ${ }^{6}$. Competence is the capability to do something effectively or proficiently ${ }^{7}$. While in the clinical context, it is described as the ability to make acceptable, reasonable, and efficient choices or to implement a dexterity in a particular situation or circumstances ${ }^{8}$.

According to Westera, 2001, competence expected individuals to think about their ability, expertise and performance ${ }^{9}$, while Epstein express competence in more scientific perspective as persistent and thoughtful use of comprehension, 
communication, pragmatic skills, scientific rational, feelings, standards, and perception in daily routine for the advantage of the individual person and society being assisted ${ }^{10}$. According to Hager \& Gonczi, 1996, it was highlighted that in medical teaching and evaluation of literature, competency should precisely be intended for the skill while competence should be the ability to act effectively in a situation, and the attributes of the facilitator ${ }^{11}$. Therefore, the proficiency of neonatal resuscitation is the competency while the semi-skilled birth attendant's capability to execute this skill is the competence of performing it. About $10 \%$ newborns have absent or even poor respiratory efforts that require support to achieve cardiopulmonary stability out of approximately 136 million babies born globally ${ }^{12}$.

The International Conference on Population and Development in 1994 established a number of goals and objectives which include universal access to comprehensive reproductive health services with reduction in maternal and perinatal mortality and morbidity which must be attained by $2015^{12}$. It was estimated that about $90 \%$ of newborns make the transition from intrauterine to extrauterine life without any intervention, although this effective transition is influenced by some factors that include the health of the mother, the pregnancy, and the labor process, even though healthy foetus can tolerate some intrapartum hypoxia remarkably well ${ }^{13}$. Nevertheless, severe lack of oxygen during labour may progress to Ischaemic-hypoxia injury in a non-breathing baby. According to Lawn et al, the critical period of newborn survival is the first day, especially the first hour with $60 \%$ to $70 \%$ increase in risk of intrapartum-related newborn deaths occurring within 24 hours of birth ${ }^{14}$. In their systematic study of long-term neurodevelopmental outcomes after intrauterine and neonatal insults, Mwaniki et al stated that the common causes of newborn deaths are birth asphyxia, infection, and prematurity ${ }^{15}$. Although, birth asphyxia, or failure to initiate or sustain spontaneous breathing at birth, causes approximately $27 \%$ to $30 \%$ of newborn deaths, and significantly contributes to neurodevelopmental disabilities in survivors. Birth asphyxia occurs between the beginning of labour and the delivery of the placenta, and a major cause of neonatal morbidity and mortality as well as the primary cause of intrapartum stillbirths ${ }^{16}$.

Helping Babies Breathe (HBB) is an evidence-based program for neonatal resuscitation. It was a model created to train health professionals in low-resource settings ${ }^{16}$. The strategy scheme is dominant on basic care for all babies including drying, warmth, stimulation and suctioning, while ventilation is within the main 'Golden Minute' of life ${ }^{17}$. Studies conducted to evaluate HBB showed decrease in neonatal mortality ${ }^{18}$. Conversely, HBB training alone cannot absolutely alleviate the divergence in care associated with neonatal mortality. In Kamath-Rayne et al article, helping babies breathe was described as a proficiency program in neonatal resuscitation for birth attendants in low-resource settings, which has been performed in over 80 countries since $2010^{19}$. In many HBB studies implementation, it was found to incorporate a capacity-building method that encourage the best recollection of scientific knowledge, and skills by means of focused visual reality learning activities, and valued enhancement showed significant decline in mortality resulting from fresh stillbirth and first-day neonate ${ }^{19}$. Even though neonatal resuscitation has a potential intervention to revive newborn lives and to decrease harm, the prevalent and effective execution has been so difficult in low-resource settings. The skill-based aspect of HBB emphases on improving birth attendants' knowledge of essential resuscitation expertise by means of effective learning with motivation, highlighting usual pattern of action with peers to build up a teamwork with good understanding, and insightful knowledge with determination ${ }^{19}$. The aim of this study is to test and refine existing neonatal resuscitation model for semi-skilled birth attendants in rural Nigeria. The goal is to particularly improve neonatal care through enhancement of educational efficacy, intensify implementation plans and make available model for continuous development of perinatal education programmes.

\section{Methods}


This purpose of the study was to refine the existing neonatal resuscitation model for the training of semi-skilled birth attendants in rural communities in Oyo State, Nigeria. It was conducted among semi-skilled birth attendants in Primary Health Care centre in Ibadan. It was a community-based study where health extension workers were assessed before a neonatal resuscitation training was conducted. This study employed a mixed-method design in which the qualitative data enhanced by quantitative data in a sequential approach.

\section{Setting}

This study was conducted in Primary Health Care centres of fifty-two (52) Local Government Areas of Oyo State, Nigeria.

\section{Study Design:}

This study employed descriptive, non-experimental research design to collect data for the quantitative component of the questionnaire to realise the objective while qualitative component, focus group discussion and in-depth interview were used ${ }^{20}$. It involved the concurrent but separate collection and analysis of the quantitative and qualitative data. The purpose of concurrent triangulation design was to obtain different but complimentary data on the same topic ${ }^{21}$ to best address the research problem. This design brought together strengths of the quantitative and qualitative methods 22. The researcher used the two data types to substantiate each other. This study used the convergence model variant of triangulation by collecting and analyzing both quantitative and qualitative data to test and refine a suitable model for training with the different results converging during interpretation.

The target population for this study were community health extension workers in a low income community setting. Two (2) participants each were purposefully selected from each PHCs who met the inclusion criteria and were willing to participate, making a total of 110. All participated in the questionnaire which included demographic characteristics of each participant, knowledge of newborn care and neonatal resuscitation. A structured self-administered questionnaire was adapted from Neonatal Resuscitation Training (NRT) and Helping Babies Breathe (HBB) modules of the American Academy of Paediatrics and WHO practical guide on basic newborn resuscitation. It was provided in both English and local language of Yoruba, and each participant was asked to decide in which language they would like to answer the questions. The raw data was captured on an Excel worksheet by the researcher and analysed with SPSS Version 21 program by the statistician.

Focus group discussions were conducted with a group of fifteen (15) CHEWs. The discussions were accompanied by in-depth interviews with ten (10) CHEWs from the main sample. These interviews were carried out after intervention was instituted (HBB training) and the results obtained contributed to the refining of training model. This study tested the simplified HBB neonatal resuscitation protocol of the American Academy of Paediatrics and adapted two (2) interventions: the Cambodian conceptual model and Nepal model of NR. A suitable model was created for birth attendants in Nigeria from Cambodia model.

The study was approved by both the University of KwazuluNatal (UKZN) Biomedical Research Ethics Committee, where the researcher is a student and Oyo State Ethical Committee in Nigeria. All participants were asked to provide a written informed consent prior to participation in the study.

\section{Training programmes}

A training program was carried out at each local government area that was attended by the selected semi-skilled birth attendants, and was conducted in Yoruba language, the local language. The content of the training was adapted from 
American Academy of Paediatrics ${ }^{23}$, same was modified to suit non-hospital based primary care and rural settings. It included lectures, demonstrations using mannequins, and each participant's hand-on practical demonstrations.

Model of knowledge translation, implementation and on-going monitoring was used to assess knowledge and skills of semi-skilled birth attendants. This model is also known as the Utestein formula of survival ${ }^{24}$ that states that patient's outcome is a product of medical science, educational efficacy, and implementation (Fig 1) ${ }^{24}$. The American Heart Association (AHA) and American Academy of Paediatrics through the ILCOR/WHO guidelines present the medical evidence in form of HBB stimulation-based education programme, and was applied to educate and train the semiskilled attendants in order to exploit the knowledge in managing asphyxiated newborn ${ }^{23,25}$. This model intensified the knowledge of semi-skilled birth attendants through training received and sufficiently equipped them for immediate neonatal stability through resuscitation especially in their various settings.

The model was employed for knowledge translation, ability to apply the knowledge, ongoing monitoring as well as attention to quality care which tackled the gap identified in the study.

The identified gaps of neonatal resuscitation in this study setting that were refined are summarized below:

Identification of at risk mothers

- Antepartum factors e.g Maternal diabetes, Hypertension, Bleeding, Maternal infection (malaria, HIV etc), Multiple gestation, Premature rupture of membrane etc.

Identification of at risk babies

- Intrapartum factors e.g Breech presentation, Premature labour, Meconium-stained liquior, Prolapse of the cord, Significant bleeding etc.

Cord clamping

- Timing of cord clamping and cutting

- Resuscitation with the cord intact

Stimulation

- Appropriate way to stimulate

- Successful stimulation

Suctioning

- Management of meconium-stained liquor

Post-resuscitation care

- Routine care

- Close observation on mother's chest

\section{Education}

- Helping babies breath action plans and guidelines be displayed at strategic areas

- Frequent training and re-training 
- Frequent use to retain skills

\section{Observations}

Observation of respondents were done immediately after the initial training to evaluate their immediate knowledge and skills through hands-on practical training with the mannequin. Observation was repeated at six (6) weeks to evaluate their skills retention. An intervention was instituted through refining and improvement on the training model. The refined training model was tested at twelve (12) and sixteen (16) weeks respectively.

Kirkpatrick model for evaluation of education programmes ${ }^{26}$ was used to evaluate semi-skilled knowledge translation and behavioural changes using four levels of evaluation. The levels include:

1. Reactions

2. Learning

3. Transfer

4. Result

Kirkpartrick model was developed by Donard Kirkpatrick in 1959, and updated several times. The 2006-updated version was used for this study ${ }^{26}$. In this model, the four evaluation levels give a detailed understanding of the effectiveness of the training programme and possible needs for amendment and further development. According to the model, evaluation should begin with one level to another in a sequential way, as time and budget allows, while information and evidence from one level will work together as a foundation and support for the next level of evaluation.

\section{Level 1 evaluation: Reactions}

Reaction level assessed how participants in a training respond. This level try to answer questions regarding the participants' perception. In this present study, qualitative questions on perception of respondents were asked, and their various responses stated under results. The training was well perceived by all respondents, and their reactions to the training was good. According to Kirkpatrick, every training programme should be evaluated at this level to support enhancement and progress of the training programme because the reactions of participants have an important consequence for learning.

\section{Level 2 evaluation: Learning}

According to Kirkpatrick, assessment at this level changed the evaluation away from learner contentment under reaction level. It tried to evaluate the level at which participants have developed in skills, knowledge, or attitude. It varies from formal to informal testing to team assessment and self-assessment. This may take the form of test before and after training.

In this study, the extent to which respondents' had improved in skill and knowledge was carried out through the pre-test before the training to assess the baseline knowledge of neonatal resuscitation. Post-test was done after the training to verify the quality of learning received.

\section{Level 3 evaluation: Transfer}

This level evaluated if knowledge and skills transfer had occured in learners' behavior as a result of the training programme. According to Kirkpatrick model, evaluating at this level made effort to answer the question: are the newly 
acquired skills, knowledge, or attitude being used in the everyday environment of the learner?. Unfortunately, most times, it is challenging to assess this level of evaluation because time and period of change in behavior cannot be anticipated. Therefore, vital decisions need to be taken to plan the assessment. In this study, observations of participants were carried out at their various PHC centers, to assess their skills of resuscitation. In HBB, relevant practical learning is expectantly transferred into clinical practice, thereby improving newborn outcome in level 4 (result).

\section{Level 4 evaluation: Results}

This level measured the achievement of the training programme in terms of reduced mortality and morbidity. HBB is a practical stimulation-based training that involves the creation and utilization of knowledge and tasks according to a scenario, thereby bringing together theoretical, cognitive, technical, and behavioural skills into a dynamic situation. In this study, the one day training is sufficient to improve overall resuscitation performance of semi-skilled birth attendants. The success of the training was measured at sixteen (16) weeks with a positive newborn outcome.

\section{The Neonatal Resuscitation Training Model}

The neonatal resuscitation training model for this study adopted Helping Babies Breathe (HBB) model.

It is an evidence-based informative program to impart neonatal resuscitation procedures in low-resource setting. HBB is a project of the American Academy of Paediatrics in discourse with the World Health Organization and in association with US Agency for International Development (USAID), Saving Newborn Lives/Save the Children, the National Institute of Child Health and Development (NICHD) and many other health stakeholders worldwide 23,27 . It aims to help meet Sustainable Development Goal 17 targets for reduction of child mortality by addressing one of the most important causes of neonatal mortality resulting from birth asphyxia. It teaches the easy actions that successfully revive greater number of infants not breathing at birth ${ }^{23}$. The event is intended to synchronize with other interference in a collection carefully chosen to enhance neonatal and maternal health. HBB can be utilized as the resuscitation constituent in the content teaching Essential Newborn Care (ENC) ${ }^{28}$ and subjects in midwifery training. It can be utilized at all stages in the health system. It expands resuscitation training to community health care services, and health personnel in low-income settings, where proficient are extremely deficient. This can also be executed in tertiary health care facilities, wherever it accompaniments, nevertheless it does not substitute complete resuscitation study programs such as the Neonatal Resuscitation Program (NRP). Both HBB and NRP demonstrate the similar first steps in resuscitation however NRP contains the utilization of supplemental oxygen, chest compression, intubation, and medications ${ }^{23}$. HBB employ a student-centred learning approach with prominence in understanding the basic proficiency. Pictographic, inexpensive, and high-standard neonatal simulator device occupy trainee as well as enable them to maintain acquired knowledge in the place of work. It fortifies regular procedure, utilize job aids support, simulator devices, with mannequins obtainable in the place of work to sustain proficiency ${ }^{23}$.

There are critical concerns that need to be implicit in respect to neonatal resuscitation. These include preliminary readiness of the delivery ward for probably neonatal resuscitation at birth and the testing of essential and vital kit neonatal resuscitation. After the delivery of a neonate, drying, airways clearance as well as invigorating breathing are done. Also, within one minute of a birth, the birth attendant requires to effectively deliver bag and mask ventilation if the need is identified ${ }^{29}$. In reviving the neonates, a birth attendant must understand which techniques to keep to as summarizing in neonatal resuscitation guidelines. The most significant understanding of 'The Golden Minute' in neonatal resuscitation; which strive to make sure that a neonate who does not begin breathing regardless of meticulous drying and further stimulation, establish a positive-pressure ventilation to begin breathing within one 
minute of a delivery ${ }^{30}$. In neonatal resuscitation, an attendant ought to be aware of the practical method to adhere to in the resuscitation of neonates as stipulated in basic HBB. HBB make certain that an attendant is skilled to make ready a mother who is in labour for delivery, and take care of a neonate in a suitable time limit. It highlights instant evaluation of the neonate, motivate to breathe and the requisite for neonatal bag and mask ventilation, observing and assist, entirely around 'The Golden Minute' after delivery ${ }^{31}$. The principal aim of utilizing HBB stems from the scientific basis of neonatal resuscitation which is premised on neonatal evidence-based guidelines set out by the International Liaison Committee on Resuscitation (ILCOR) ${ }^{31}$.

These guidelines aimed at:

- improving maternal and newborn health

- improving the care provided in the households by women and families

- advancing community support for maternal and newborn health

- enhancing access to, and use of skilled care, community care, especially with curative services that can prevent around $25 \%$ of neonatal deaths ${ }^{32}$.

Meanwhile, secondary prevention of neonatal deaths, which is based on immediate basic resuscitation of a nonbreathing newborn baby, can efficiently reduce a large percentage of neonatal deaths. The easiness in the application of the basic resuscitation procedure by health workers appears to be the most effective in achieving ideal results ${ }^{31}$. For the programme on newborn stabilization and support to succeed in a resource-limited setting, practitioners can make the difference between life and death by following the basic steps of helping a baby to breathe through the use of HBB model. Knowledge of the use of the educational kit, the HBB and the mandatory skills needed are to be designed to the extent to which they could meet the anticipated level of competency ${ }^{31}$. The World Health Organization (WHO) has developed guidelines on newborn resuscitation, on how to handle a non-breathing neonate at birth. According to WHO, there is overwhelming evidence that the HBB has eloquently improved perinatal outcomes ${ }^{33}$.

\section{Results}

\section{Table 1: Socio-demographic Characteristics of respondents}




\begin{tabular}{|l|l|l|l|l|l|}
\hline Age (Year) & $\mathbf{n}$ & \% & $\mathbf{p}$-value & Mean & Std devt \\
\hline$<40$ & 17 & 15.5 & 0.043 & 45.36 & 6.734 \\
$40-49$ & 62 & 56.4 & & & \\
$>=50$ & 31 & 28.2 & & & \\
\hline Educational level & & & & & \\
\hline Secondary & 5 & 4.5 & 0.000 & 3.34 & 0.563 \\
Technical & 63 & 57.3 & & & \\
Others & 42 & 38.2 & & & \\
\hline Designation & & & & & \\
\hline Senior CHEWs & 87 & 79.1 & 0.000 & 1.21 & 0.409 \\
Junior CHEWs & 23 & 20.9 & & & \\
\hline Years of experience & & & & & \\
\hline$<10$ years & 14 & 12.7 & $\mathbf{0 . 0 0 0}$ & 2.28 & 0.814 \\
10-19 years & 62 & 56.4 & & & \\
20-29 years & 23 & 20.9 & & & \\
$>=30$ years & 11 & 10.0 & & & \\
\hline Gender & & & & & \\
\hline Male & 7 & 6.4 & $\mathbf{0 . 0 0 0}$ & 1.94 & $\mathbf{0 . 2 4 5}$ \\
Female & 103 & 93.6 & & & \\
\hline
\end{tabular}

All participants completed the training, observed for immediate practice, involved in eight (8) and also sixteen (16) weeks practice observation. All respondents were trained in neonatal resuscitation, participated in the immediate post training test and observed at their different PHC centres eight (8) and sixteen weeks after training, giving a response rate of $100 \%$. Although, all responded completed the questionnaires administered to them, which were described in another sub-set study with poor pre-test score. Less than $50 \%$ of them were below age 40 years (15.5\%) and more than or equal to 50 years old (28.2\%) with a mean age of $45.4 \pm 2.1$ years and median age of 45 years. Majority of them were senior CHEW (79.1\%) with post-secondary education. Over half of them (56.4\%) have spent between 10-19 years working as birth attendants at different PHC centres, out of which only $7(6.4 \%)$ were male $(p<0.000)$. This indicate that respondents are matured health care providers, educated with at least the lowest approved level of education in Nigeria. The profession is more female dominated, and been a community service based, culturally, community people feel secured and can entrust their own in the hands of female than male gender. They can only allow a female health providers take delivery of pregnant woman and visit their homes (Table 1).

Table 2: Age $(\mathrm{n}=110)$

\begin{tabular}{|l|l|l|l|l|l|l|l|}
\hline $\mathbf{n}$ & Mean & SD & Minimum & $\mathbf{2 5}^{\text {th }}$ percentile & Median & 75 $^{\text {th }}$ percentile & Maximum \\
\hline 110 & 45.36 & 6.734 & 26 & 40.00 & 45 & 50.00 & 59 \\
\hline & & & & & & & \\
\hline
\end{tabular}


Table 2 showed the descriptive statistic of respondents, with mean age of 45.36 years and standard deviation of 6.734. The median is 45 years and the percentile range from $25 \%$ to $75 \%$ is $40-59$ years with the youngest being 26 years and the oldest is 59 years (Table 2).

Table 3: Knowledge of neonatal resuscitation

\begin{tabular}{|l|l|l|l|l|}
\hline & $\begin{array}{l}\text { Pre } \\
(\%)\end{array}$ & $\begin{array}{l}\text { Post } \\
(\%)\end{array}$ & $\begin{array}{l}\mathbf{X}^{2} \\
\text { value } \\
\text { value }\end{array}$ \\
\hline Managing a baby born through meconium stained amniotic fluid. & $\begin{array}{l}12 \\
(10.9)\end{array}$ & $\begin{array}{l}94 \\
(85.5)\end{array}$ & 0.000 \\
\hline What should you do in Golden minute & $\begin{array}{l}15 \\
(13.6)\end{array}$ & $\begin{array}{l}94 \\
(85.5)\end{array}$ & \\
\hline $\begin{array}{l}\text { Managing a newborn baby who is quiet, limp and not crying. The baby } \\
\text { does not respond to steps to stimulate breathing. }\end{array}$ & $\begin{array}{l}16 \\
(14.5)\end{array}$ & $\begin{array}{l}110 \\
(100)\end{array}$ & & \\
\hline $\begin{array}{l}\text { Which of the following statements about ventilation with bag and masks } \\
\text { is TRUE? }\end{array}$ & $\begin{array}{l}18 \\
(16.4)\end{array}$ & $\begin{array}{l}91 \\
(82.7)\end{array}$ & & \\
\hline $\begin{array}{l}\text { A baby's chest is not moving with bag and mask ventilation. What should } \\
\text { you do? }\end{array}$ & $\begin{array}{l}42 \\
(38.2)\end{array}$ & $\begin{array}{l}103 \\
(93.6)\end{array}$ & & \\
\hline When do stop ventilation & $\begin{array}{l}15 \\
(13.6)\end{array}$ & $\begin{array}{l}96 \\
(87.3)\end{array}$ & \\
\hline What should you do to keep the baby warm & $\begin{array}{l}17 \\
(15.5)\end{array}$ & $\begin{array}{l}101 \\
(91.8)\end{array}$ & \\
\hline An appropriate way to stimulate a baby that is not breathing & $\begin{array}{l}16 \\
(14.5)\end{array}$ & $\begin{array}{l}109 \\
(99.1)\end{array}$ & \\
\hline
\end{tabular}

The above showed the knowledge of CHEWs in critical areas of resuscitation before and after the training. Before the training, majority of them lacked knowledge of what to do when a baby is born with meconium stained liquor, what golden minute signified in neonatal resuscitation, when to begin ventilation of asphyxiated baby and how to stimulate baby that is not breathing. But post-training assessment showed that there was a significant improvement in their knowledge of newborn resuscitation (Table 3).

Table 4: Method of resuscitation

\begin{tabular}{|l|l|l|l|}
\hline Method & Pre (\%) & Post (\%) & Std dvt \\
\hline Slapping/ beating the buttocks & $73(66.4)$ & $25(22.7)$ & 0.77 \\
\hline Head down & $73(66.4)$ & $25(2.7)$ & 0.74 \\
\hline Vigorous shaking & $43(30.1)$ & $13(11.8)$ & 0.57 \\
\hline Suctioning the airways & $102(92.7)$ & $96(87.3)$ & 0.59 \\
\hline Mouth-to mouth breathing & $93(84.5)$ & $68(61.8)$ & 0.68 \\
\hline
\end{tabular}


Respondents' previous practice of resuscitation showed that majority of them engaged in harmful resuscitation practices, while majority (66.4\%) slap/beat the newborns' buttocks and put babys'heads down as an alternative way of resuscitating asphyxiated neonates, while suctioning the airway is one of the routine care for every newborn, which they were trained to perform on every newborn (Table 4).

Table 5: Cumulative knowledge score by respondents age, level of education and years of experience before the training

\begin{tabular}{|l|l|l|l|l|l|}
\hline Age & \multicolumn{2}{|l|}{ Knowledge of NR } & $\mathbf{X}^{2}$ & df & p-value \\
\hline & Good & Poor & 1.290 & 2 & 0.525 \\
\hline$<40$ & $2(1.8)$ & $15(13.6)$ & & & \\
\hline $40-49$ & $9(8.2)$ & $53(48.2)$ & & & \\
\hline$>=50$ & $2(1.8)$ & $29(26.4)$ & & & \\
\hline Education & & & & & \\
\hline Secondary & $3(2.7)$ & $2(1.8)$ & 13.191 & 2 & 0.001 \\
\hline Technical & $4(3.6)$ & $59(53.6)$ & & & \\
\hline Others & $6(5.5)$ & $36(32.7)$ & & & \\
\hline Years of Experience & & & & & \\
\hline$<10$ years & $2(14.3)$ & $12(85.7)$ & 0.210 & 3 & 0.976 \\
\hline $10-19$ years & $7(12.9)$ & $55(50.0)$ & & & \\
\hline $20-29$ years & $3(2.7)$ & $20(18.2)$ & & & \\
\hline$>=30$ years & $1(0.9)$ & $10(9.1)$ & & & \\
\hline
\end{tabular}

All respondents had deficient knowledge of NR, out of which majority were between the ages of 40-49 years, those with technical education 59 (53.6\%) and with years of experience of 10-19 years. This implied that even though they have been working for so long with additional educational qualifications and matured ages, this does not translate to acquiring knowledge of resuscitating newborns since there was no evidence of in-service training education that can improve their neonatal resuscitation knowledge (Table 5).

Table 6: Area wise observation score, immediately and 8 weeks after training 


\begin{tabular}{|c|c|c|c|c|c|c|c|}
\hline \multirow[b]{2}{*}{ Observation } & \multicolumn{2}{|c|}{$\begin{array}{ll}\text { Practice } & 1 \\
\text { (immediately } & \\
\text { after training) } & \end{array}$} & \multicolumn{2}{|c|}{$\begin{array}{l}\text { Practice } 2(8 \\
\text { weeks for model } \\
\text { testing) }\end{array}$} & \multicolumn{2}{|c|}{$\begin{array}{lrr}\text { Practice } 4 & (16 \\
\text { weeks } & \text { for } \\
\text { evaluation } & \text { of } \\
\text { model) } & \end{array}$} & \multirow[t]{2}{*}{$\begin{array}{l}\mathrm{p}- \\
\text { value }\end{array}$} \\
\hline & $\mathrm{D}(\%)$ & $\begin{array}{l}\text { ND } \\
(\%)\end{array}$ & $\mathrm{D}(\%)$ & ND (\%) & $\mathrm{D}(\%)$ & ND (\%) & \\
\hline $\begin{array}{l}\text { How to prepares for } \\
\text { birth/delivery }\end{array}$ & $\begin{array}{l}107 \\
(97.4)\end{array}$ & $3(2.7)$ & $\begin{array}{l}28 \\
(25.5)\end{array}$ & $\begin{array}{l}82 \\
(74.5)\end{array}$ & $110(100)$ & & 0.000 \\
\hline $\begin{array}{l}\text { How can you recognize baby is } \\
\text { not crying }\end{array}$ & $\begin{array}{l}107 \\
(97.4)\end{array}$ & $3(2.7)$ & $\begin{array}{l}14 \\
(12.7)\end{array}$ & $\begin{array}{l}96 \\
(87.3)\end{array}$ & $107(97.3)$ & $3(2.7)$ & \\
\hline $\begin{array}{l}\text { Keep warm, positions head, } \\
\text { clears airway }\end{array}$ & $\begin{array}{l}95 \\
(86.4) \\
\end{array}$ & \begin{tabular}{|l}
15 \\
$(13.6)$ \\
\end{tabular} & $7(6.4)$ & $\begin{array}{l}103 \\
(93.6) \\
\end{array}$ & $110(100)$ & & \\
\hline $\begin{array}{l}\text { Stimulates breathing by rubbing } \\
\text { the back }\end{array}$ & $\begin{array}{l}105 \\
(95.5)\end{array}$ & $5(4.5)$ & $6(5.5)$ & $\begin{array}{l}104 \\
(94.5)\end{array}$ & $105(95.5)$ & $5(4.5)$ & \\
\hline $\begin{array}{l}\text { Cuts cord and moves to area for } \\
\text { ventilation }\end{array}$ & $\begin{array}{l}110 \\
(100)\end{array}$ & 0 & $4(3.6)$ & $\begin{array}{l}106 \\
(96.4)\end{array}$ & $110(100)$ & & \\
\hline $\begin{array}{l}\text { Starts ventilation within the } \\
\text { Golden Minute }\end{array}$ & $\begin{array}{l}110 \\
(100)\end{array}$ & 0 & $\begin{array}{l}24 \\
(21.8)\end{array}$ & $\begin{array}{l}86 \\
(78.2)\end{array}$ & $110(100)$ & & \\
\hline Looks for chest movement & $\begin{array}{l}110 \\
(100)\end{array}$ & 0 & $5(4.5)$ & $\begin{array}{l}105 \\
(95.5)\end{array}$ & $110(100)$ & & \\
\hline $\begin{array}{l}\text { Repositions head, clears } \\
\text { secretions, opens mouth slightly, } \\
\text { squeeze bag harder }\end{array}$ & $\begin{array}{l}110 \\
(100)\end{array}$ & 0 & $\begin{array}{l}15 \\
(13.6)\end{array}$ & $\begin{array}{l}95 \\
(86.4)\end{array}$ & $110(100)$ & & \\
\hline $\begin{array}{l}\text { Stops ventilation; monitors baby } \\
\text { and communicates with mother }\end{array}$ & $\begin{array}{l}109 \\
(99.1)\end{array}$ & $1(0.9)$ & $\begin{array}{l}11 \\
(10.0)\end{array}$ & $\begin{array}{l}99 \\
(90.0)\end{array}$ & $110(100)$ & & \\
\hline
\end{tabular}

*** $1^{\text {st }}$ practice: Std dev of diff $=2.9 ;$ Mean diff $=3.3$

$2^{\text {nd }}$ practice: Std dev. of diff $=$; Mean diff $=2.37$

$4^{\text {th }}$ practice: Std dev. of diff $=$; Mean diff. $=3.27$

The above showed the respondents' observations scores immediately after training, eight (8) weeks after the initial training and sixteen (16) weeks when interventions were instituted. All of them performed very well immediately after the training in resuscitation using mannequins. Those that did not do well were re-trained on the aspect of deficiencies and reassessed. At eight (8) weeks, when they were assessed at their various PHCs centers, majority did not perform adequately well. At sixteen weeks, when the refined module had been used, almost all respondents performed adequately well $(p<0.000)$ (Table 6). 
Table 7: Cumulative knowledge score of neonatal resuscitation and newborn care before and after the training

\begin{tabular}{|l|l|l|l|l|l|}
\hline Neonatal resuscitation & Pre-test & $\%$ & Post-test & $\%$ & p-value \\
\hline Good & 13 & 11.8 & 106 & 96.4 & 0.000 \\
\hline Poor & 97 & 88.2 & 4 & 3.6 & \\
\hline & & & & & \\
\hline Newborn care & & & & & \\
\hline Good & 13 & 11.8 & 104 & 94.5 & 0.000 \\
\hline Poor & 97 & 88.2 & 6 & 5.5 & \\
\hline
\end{tabular}

Out of 110 that were trained, almost all had a very good knowledge of newborn care both before and after training. On the contrary, their knowledge of resuscitation was poor at pre training, but had improved knowledge at post training (Table 7).

\section{Qualitative data}

Table 8: demographic characteristics of FGD and IDI respondents

\begin{tabular}{|l|l|l|}
\hline Demographic Characteristics & $\mathrm{n}$ & $\%$ \\
\hline Age (Years) & & \\
\hline $25-35$ & 3 & 12 \\
\hline $35-45$ & 8 & 32 \\
\hline $45-55$ & 12 & 48 \\
\hline $55-65$ & 2 & 8 \\
\hline Educational Level & & \\
\hline Secondary & 4 & 16 \\
\hline Technical & 15 & 60 \\
\hline Others & 6 & 24 \\
\hline Years of experience & & \\
\hline$\leq 10$ & 2 & 8 \\
\hline $10-19$ & 12 & 48 \\
\hline $20-29$ & 9 & 36 \\
\hline$\geq=30$ & 2 & 8 \\
\hline Designation & & \\
\hline Senior CHEW & 20 & 80 \\
\hline Junior CHEW & 5 & 20 \\
\hline Religion & & \\
\hline Christianity & 19 & 76 \\
\hline Islam & 6 & 24 \\
\hline Others & - & \\
\hline
\end{tabular}


The respondents shared their knowledge and experiences of neonatal resuscitation after intervention was instituted. The themes that emerged were knowledge of how to stimulate a newborn, knowledge of how to ventilate a compromised baby and perception of training received. The five main themes are shown in (Table 8).

\section{Table 9: Qualitative themes}

\begin{tabular}{|l|}
\hline \multicolumn{1}{|c|}{ Themes } \\
\hline Knowledge of how to stimulate a newborn \\
\hline Knowledge of how to ventilate a compromised baby \\
\hline Perception of training received \\
\hline Suggestions for improved neonatal resuscitation in PHCs in Nigeria \\
\hline Challenges experienced in newborn care \\
\hline
\end{tabular}

In this qualitative strand, respondents shared their knowledge of newborn care and their insight of neonatal resuscitation. This theme is major focus of the refining of NRT model for the training of semi-skilled birth attendants. Under this theme, respondents' reactions and responses were discussed following their knowledge of NR including how to stimulate a newborn, how to ventilate a compromised baby, their perception of training received, challenges they experienced in newborn care and their suggestions for improved NR in PHCs in Nigeria.

Knowledge of how to stimulate a newborn: Participants mentioned that prior to training; they stimulated a newborn by slapping the baby on the back or the buttocks. However, following the training they had received they rub the back of the baby gently as against slapping. This is evident in their quotes as expressed below:

Fifty-five year old senior CHEW, who has been working for 31 years said:

"Since you said we should not slap the buttocks or shake the baby but to rub them, we have been rubbing them especially their back". (IDI_SENIOR CHEW (31YOE) 55YEARS OLD) Another respondent, a 45 year old senior $\mathrm{CHEW}$ with 17 years working experience said:

"We stimulate by rubbing the nose of the baby with spirit, the baby will sneeze and start crying. We can also rub or tap the baby for him to cry".

M- What about rubbing the back that we taught you or tapping the sole of his feet?

"Yes, it's true, we rub the baby. I told you earlier that we rub, it is the back and leg". 
M- Do you slap or shake the baby?

"Well, before now, we used to slap their buttocks but you told us that we should

not do it again, we have stopped. We only rub the baby". (IDI SENIOR CHEW (17YRS) 45YEARS).

While a 54 year old senior CHEW responded that:

"Since you said we should not slap the buttocks or shake the baby but to rub them,

we have been rubbing them especially their backs. But some of us still use

methylated spirit cotton wool to rub the ridge of the nose, for baby to sneeze and

breathe well". (IDI SENIOR CHEW (22YRS) 54YEARS)

Knowledge of ventilation of compromised newborn: Respondents' reported that they do not have the equipment necessary for the ventilation of newborns. Therefore, following the training received, they have learnt to improvise by using mucous extractors. Participants also mentioned that sometimes they practice mouth-to-mouth ventilation for the newborns.

A senior CHEW with 31 years of working experience said:

"We don't have ambu-bags, so what we do is to use mucous extractor to clear the airway and do mouth-to-mouth for the baby". (IDI - SENIOR CHEW (31YRS)

\section{YEARS)}

While another respondent said that:

"Because we don't have what we can use to ventilate, we normally use mucous extractor to clear the airways and rub baby or we do mouth-to-mouth for the baby. If it is not possible, we refer out to secondary facility for further treatment".

\section{(IDI - SENIOR CHEW (17YRS) 45YEARS)}

In Oke- Adu PHC, a 56 year old Junior CHEW, with 15 years of working experience said;

"Ha, we stimulate through the use of mucous extractor. You know I mentioned it earlier on that we don't have ambu-bag. So for us in our PHC, we don't want to lose the baby, so we do all we could to revive the baby and to do it in a way that will not injure or inflict injuring on the baby. When we have a compromised baby, we will suck the airways again and do mouth-to-mouth ventilation, provided we know her Hepatitis B and HIV statuses. This has been working for us since our last 
or not breathing well". (IDI - JUNIOR CHEW (15YRS)_ 56YEARS)

Perception of training received: All participants across the FGD and IDI agreed that the training received was important and useful in helping them carry out their responsibilities in caring for newborns and resuscitate compromised babies.

Each of them expressed themselves as follows:

"Yes ma it is useful" (R1, FGD)

"The training was useful and worth doing. Thank you very much ma for doing this

for us. (R1, FGD)

"This study and training was useful to me and my people at our center". (R2, FGD)

"It is useful to me". (R3, FGD)

"Very good training, very useful and worth it". (R4, FGD)

"This study and training was useful and worth it". (R5, FGD)

"Very good training ma". (R6, FGD)

"Yes, it has been useful, but I want the organizer to do this training again". (R7, FGD)

\section{FGD GROUP B}

Participants described how they performed neonatal resuscitation prior to the training they had just received.

"Ha, ma, all of us have a way of taking care of those babies before we attend this

training". (R4, FGD)

"In my center, we shake the babies upside down or we may give a slap at the buttocks or we use cold water to touch the legs. We believe that the babies will cry and they do cry after this, after which they start breathing very well. It works for us anyway. But after the training we have been doing it the way we were taught". $(R 4, F G D)$

"In my own case, at our center, before we came for this training, we normally shook the baby upside down and slapped the buttock at the same time. So whenever we saw an asphyxiated baby, this was what we did. We suctioned the airways too. But since we were trained, we have been suctioning the airways gently, rub the back of the 
baby and do mouth-to-mouth, since we don't have ambu-bag to do this. (R1, FGD)

\section{FGD GROUPA}

Furthermore, respondents mentioned that apart from teaching them new methods in caring for newborns, they have learnt to improvise and use what is available in terms of equipment to achieve the care to be provided.

Suggestions for improved neonatal resuscitation in PHCs in Nigeria: Participants made several suggestions they believe would be important and helpful in improving the practice of neonatal resuscitation in PHCs across the country. The suggestions raised were provision of items of equipment such as Ambu-bags; employment of staff; training and re-training of staff; participants also asked for job aids in addition to employment of more staff.

From Oje, PHC, a 55 year old senior CHEW, with 31 years of working experience said

"My suggestion is that Government should provide enough instruments and employ more staff. Then, the training you gave us, we need something that will enable us to remember those steps in performing neonatal resuscitation".

\section{(IDI SENIOR CHEW (31YRS) 55YEARS)}

A 45 year old from Idi-Ogungun PHC said,

"Eh, government should provide all necessary items of equipment and instruments for all

PHCs. Even those small but essential things like ambu-bag for adult and children should be provided. For us to remember NR, we need something that will remind us of what to do at every stage”.

\section{(IDI SENIOR CHEW (17YRS) 45YEARS)}

A 54 year old from Idi-ogungun PHC said.

"Although we have many PHCs in all our LGAs, there are no instruments nor items of equipment to work with. There are no drugs, gloves, methylated spirit, even electricity. So my suggestion is for government to provide all the necessary things to all PHCs. We need ambu-bags for resuscitation. Then, the training you gave us, we need something that will enable us to remember those steps in performing NR whenever need arises. It can be booklets or posters or both".

\section{(IDI SENIOR CHEW (22YRS) 54YEARS)}

While a respondent from Agbowo PHC said that

"My suggestion starts from providing enough health workers. We are short-staffed and we don't have enough staff to work in our PHCs, so government should employ more people. Another suggestion is to provide good, functioning and enough instruments and equipment".

\section{(IDI SENIOR CHEW (20YRS)48YEARS)}

A respondent from Agbowo PHC said 
"We want re-training. If we can be trained at least twice a year, I think it will be better. Apart from training and retraining, we can have booklets that we can refer to when we forget any of the steps. Then, we want something we can quickly consult, to be in our labour room, lying -in-ward and any other area that needs it, so that whenever we are doing the procedure, we can be looking at it and do the correct and acceptable procedure".

\section{"IDI SENIOR CHEW (2OYRS) 48YEARS)}

While from Iwo Road PHC a junior CHEW said

"They should employ more health workers including doctors. They should supply equipment that are essential and supply instruments to work with. Majority of outpatients believe health is free, as they (government) advertise on the media. So when they come and you ask them to buy virtually all things, they get annoyed. Some will even fight us that we are telling them lies. Government should wake up to their responsibilities".

\section{(IDI JUNIOR CHEW (12YRS) 35YEARS)}

Challenges experienced in newborn care: Participants mentioned various challenges they face in caring for neonates. Some of the challenges mentioned by participants include lack of equipment (these were the most mentioned challenges faced by participants; lack of workspace; lack of or inadequate staff; poor training for staff and harmful cultural practices.

Lack of equipment:

From Oje PHC, a senior CHEW said

"In our PHC center, some the challenges we face is lack of equipment. Many of our equipment are old and not functioning well... Another major challenge is lack of staff. Many a times, we do two or double shift. So it is very strenuous for all of us".

\section{(IDI SENIOR CHEW (31YRS) 55YEARS)}

While from Aremo PHC a respondent said

"Ha, We face a lot of challenges, one of them is that we have no equipment or let me say we don't have enough important equipment. Some items of equipment are not available, and for the available ones, they are not enough, old and not good again".

\section{(IDI SENIOR CHEW (24YRS) 49YEARS)}

Lack of workspace:

A respondent from Idi-Ogungun $\mathrm{PHC}$ said

"Another challenge is building. We want the government to quickly finish our building so we can have big space. Most importantly, we don't have enough staff to work in most of our PHCs across the country. Then, government should make health care free for our people, not to campaign and do propaganda on the Radio, but to do what they say and 
promise".

\section{(IDI SENIOR CHEW (17YRS) 45YEARS)}

While a 54 year old from Idi Ogungun PHC said

"Like in our PHC center, one of the biggest challenges as you can see is our building.

Government pulled down part of our building because it was dilapidated. They promised

to build a new one before pulling down the remaining part of the building. As you can see,

they started the new building but somehow abandoned it. So the other half of the old

building is what we are managing".

\section{(IDI SENIOR CHEW (22 YRS) 54YEARS)}

Lack of inadequate staff:

A junior CHEW from Oke-Adu PHC said

"The challenges are many, but the first is shortage of staff. We are not many and

government is not employing health care providers. No enough staff. We don't have a

doctor of our own. The local government has only one doctor and PHCs under a local

government are many. Some have 15 PHCs, some 7 PHCs, and some 8 PHCs (etc). So

you can imagine, a doctor can come to your centre maybe once in 2 weeks. So many things

we do on our own without a doctor. We normally use our initiatives and when we see that

we cannot handle a situation, we refer out".

\section{(IDI JUNIOR CHEW (15YRS) 56YEARS)}

Poor staff training:

Another junior CHEW from Oke-Adu PHC said

"We need re-training to improve the care we render..."

(IDI JUNIOR CHEW (12YRS) 35YEARS)

\section{Discussions}

Interpatum-related neonatal deaths (birth asphyxia) are the fifth most common cause of deaths among children under five years of age, out of which 814,000 deaths occur each year. Developing human capital creates economic productivity, and crucial awareness is essential in an attempt to reach every woman and newborn, to close gaps in neonatal survival coverage, and improve quality of antenatal, intrapatum, and post-natal care. Therefore, it is 
imperative to increase numbers of health workers and improve their skills with considerable high-tracking intervention coverage priority and packages of care with responsibility to fast-track progress.

Refining training of birth attendants in low-income countries is a significant intervention to reduce infant mortality rate. Resuscitation knowledge among CHEWs in Ibadan increased initially as a result of the training. Overall, this study revealed that significant percentage of respondents are above 40 years of age with majority having Technical education i.e had training in health technology, which is the requisite for certification as CHEW. Majority were senior CHEWs who have been working between 10-19 years. This indicates that almost all respondents were full-grown adults of mature state of mind with extensive experience in newborn care. This is similar to a study conducted by Uwakah \& Smee (2016) ${ }^{34}$, in Eastern part of Nigeria, where the average age of participants was $42.3 \pm 9.01$ years old with minimum age of 19 , and maximum of 60 years. Very few CHEWs were selected which is in contrast to this study, and had at least secondary school certificates.

This study showed that knowledge of neonatal resuscitation before HBB training was very poor compared to their scores after the training. This is similar to Murila et al ${ }^{29}$ in their study in Kenya where it was observed that respondents performed poorly in neonatal resuscitation. Similarly, many studies conducted also revealed poor knowledge of neonatal resuscitation among health care providers ${ }^{35}$. Similar to the study of Mirkuzie et al ${ }^{36}$ in their research study conducted in Addis Ababa, Ethiopia where it was reported that participants performance was poor on neonatal resuscitation, but in contrast with the study of Berhe et al ${ }^{37}$ study, where health care providers in public facility had a good knowledge and their performances were good. Studies conducted at various health care facilities in Kenya showed that, health care providers had poor knowledge and skills of neonatal resuscitation. For the few with good knowledge of NR, it was reported to be as a result of areas of practice and had attended a training in NR. Those working at the labour ward and newborn units were more knowledgeable in NR compared with others ${ }^{38}$. In the study of Opiyo et al ${ }^{39}$ on the effect of one-day training in neonatal resuscitation, the study outcomes showed immediate improvement in knowledge of caregivers after they were trained in NR, and this is similar to this present study ${ }^{39}$. In the study of Bhurji $2011^{38}$, it was found that the level of knowledge of NR was not significantly associated with previous training on NR, while in the study of Alwar in $2010^{40}$, it was discovered that small percentage of participants had an adequate knowledge in NR and is similar to this present study.

The performance knowledge scores worsened as they soared the practice pyramid from drying and warming with circulation in the study of Bhurji ${ }^{38}$, this is consistent with the study of Alwar ${ }^{40}$ which showed poor performance. Consistent with this present study is the result of Murila et al ${ }^{29}$ which revealed majority of providers having awareness of NR and considered their knowledge inadequate. Bhurji ${ }^{38}$ reported in his study that majority of providers were aware of NR protocols but only $57 \%$ had adequate knowledge of it and $5.7 \%$ performed the practices correctly. Also similar is the study of Uwakah \& Smee (2016) ${ }^{34}$, which found that the TBAs and other birth attendants showed improved knowledge and skill ability after the implementation of NR training compared to their scores before the training. Also similar to the present study is a study conducted in Cambodia ${ }^{41}$ among health care professionals where it was reported that the knowledge of NR before the training was very low while immediately after the training, it was significantly improved. The difference between the pre-test and post-test was significant which is consistent with this study.

This study revealed different methods of resuscitation practised by birth attendants before the training. Majority of them slapped babies' buttocks, followed by turning their heads upside down while others practiced vigorous shaking of the baby. This is similar to the study conducted by Shikuku et al 42 in Kenya where it was found that a few respondents practised inappropriate methods of resuscitation. About $8 \%$ vigorously rubbed babies' backs while 
another $2.2 \%$ flicked babies' feet. It was revealed also that, about $60 \%$ of them did not suction the airways before stimulating babies who presented with meconium - stained liquor. Some of them turned the babies' upside down, while others positioned the heads of the babies' inappropriately to facilitate airway opening. Similar to another study conducted by Bhurji, $2011^{38}$, it was observed that the participants practised outdated methods of stimulating the newborns which were harmful. They practised vigorous shaking of the baby, and suctioning inappropriately in the presence of meconium. This is in contrast to the study of Alwar ${ }^{40}$, where correct practises were observed among caregivers and it was observed to be as a result of regular in-service training of care providers ${ }^{40}$. In the study of Otido

43 conducted at a secondary facility also in Kenya, it was found out that health care providers' performances were very poor as many of them engaged in inappropriate practice of resuscitation.

In the qualitative aspect of this study, respondents claimed that there was an improvement in the rate at which they refer emergencies seen in infants to secondary facilities. Also, during the observation of participants at 16 weeks after implementation of intervention, it was noted that there was a significant improvement in the skills of birth attendants. This is similar to the study conducted in Tanzania which showed a significant reduction in the primary outcomes of early neonatal deaths in the first 24 hours, and rate of early perinatal mortality which was associated with implementation of the HBB training of health care providers ${ }^{17}$. This is also similar to the study of Bhurji $2011^{38}$,on determination on adherence to resuscitation guidelines where it was reported that health care providers had improved skills after training was instituted.

The study also showed that there was no significant relationship between age, years of experience and knowledge of neonatal but there was a significant relationship between their level of education and knowledge of neonatal resuscitation.

In this present study, observation that led to refine model of training showed that they performed very well immediately after the initial training, but when they were observed at eight (8) weeks post-training, their performances were very poor. When model was refined and evaluated at sixteen (16) weeks, their performances were very good. They improved very well on specific basics of newborn care. This is in line with the study of Mduma et al ${ }^{18}$ in their study that found out that on-site, brief and frequent HBB training appears to facilitate transfer of new knowledge and skills into clinical practice, thereby decreasing neonatal mortality ${ }^{18}$. Also similar to the study of Msemo et al ${ }^{17}$ in Tanzania, where it was reported that reduction in early newborn mortality was due to specific training elements of immediate application of basic steps such as drying, stimulation, and suctioning of the newborn contained in the HBB programme ${ }^{17}$. Although, globally, facility deliveries are not associated with successive reduction in perinatal mortality due to main quality gaps which including but not limited to inadequate staffing, extensive use of inexperienced trainees as front line workers and congested facilities.

\section{Conclusion}

Perinatal mortality accounts for an increasing proportion of mortality in neonates and infants. Current guidelines for resuscitation have some knowledge gaps which were identified in this study based on the study environment. The gaps should be addressed to give a chance of morbidity-free survival of newborns. Simple actions taken at birth are proven to be effective if properly implemented and prevent large proportion of newborns and infant deaths, thereby reducing mortality burden. Since programme implementation consumes organisation time and resources, it is important to select appropriate training for efficient practical outcomes. Also, report of training needs to be appraised according to appropriate standard. This refined model of training can be used to determine a favourable outcome of practice and improve relevant knowledge acquisition and application. 


\section{Abbreviations}

AHA: American Heart Association

AAP: American Academy of Paediatrics

CHEW: Community Health Extension Worker

ENC: Essential Newborn Care

FGD: Focus Group Discussion

HBB: Helping Babies Breathe

ILCOR: International Liaison Committee on Resuscitation

NICHD: National Institute of Child Health and Development

NRP: Neonatal Resuscitation Programme

SDG: Sustainable Development Goal

UKZN: University of Kwazulu-Natal

USAID: US Agency for International Development

WHO: World Health Organization

\section{Declarations}

\section{Availability of data and materials}

The datasets used and analysed during the current study are available from the corresponding author on reasonable request.

\section{Ethical approval and consent to participate}

The study was approved by the Biomedical Research Ethics Committee of the University of Kwazulu-Natal, Durban, South Africa and Oyo state Ministry of Health Research Ethical Review Committee, Nigeria. Written informed consent was obtained from all participants as appropriate. Ethics approval numbers are:

- BE391/18 (University of KwazuluNatal, Durban, South Africa);

- AD13/479/951 (Oyo State Research Ethics Review Committee).

\section{Acknowledgements}

The author would like to acknowledge the Discipline of Nursing, School of Nursing and Public Health, College of Health Sciences, University of Kwazulu-Natal for methodological guidance training and technical support.

\section{Funding}


This study was supported by the College of Health Sciences Scholarship, University of Kwazulu-Natal, Durban, South Africa. The institution also provide other resources and services in conducting this study.

\section{Author information}

\section{Affiliations}

School of Nursing and Public Health, College of Health Sciences, University of Kwazulu-Natal, Durban, South Africa.

Adenike Olaniyi \& Busisiwe Ncama

School of Nursing, University College Hospital, Ibadan, Nigeria.

Adenike Olaniyi

\section{Author's Contributions}

AAO conceptualised the study, responsible for literature search, supervised and participated in data collection, data analysis and prepared the manuscript under the guidance and supervision of BN. AAO and BN contributed to the development and study design of the study. BN reviewed the literature and manuscript. All authors contributed to critical revisions of the manuscript and approved the final submitted version.

\section{Corresponding author}

Correspondence to Adenike Olaniyi.

\section{Consent for publication}

Written informed consent was obtained from all participants for publication of data.

\section{Completing interests}

The authors declare that they have no competing interests.

\section{References}

1. Close, $\mathrm{K}$, Karel, White, M. A pilot program of knowledge translation and implementation for newborn resuscitation using US Peace Corps volunteers in rural Madagascar. Global Health. 2016: 12:73

2. Nutbeam D. Health Promotion Glossary. Health Promotion. 1986:1(1) Oxford Univ Press

3. Australian Health Promotion Association. Core competencies for health promotion practitioners. Australian Health Promotion Association [Internet]. 2009. Available from:

http://www.healthpromotion.org.au/images/stories/pdf/core\%20competencies\%20for\%20hp\%20practitioners.pdf

4. Ottawa Charter for Health Promotion. First International Conference on Health Promotion, Ottawa. 1986. http://www.who.int/hpr/doc/ottawa.hml

5. Jakarta Declaration on Leading Health Promotion into the $21^{\text {st }}$ Century. Fourth International Conference on Health Promotion. Jakarta. 1997.

6. Barry MM, Allegrante JP, Lamarre MC, Auld ME, Taub A. The Galway Consensus Conference: international collaboration on the development of core competencies for health promotion and health education. Glob Health Promot. 2009; 16(2):5-11. 
7. The Oxford English Dictionary

8. Khan, K \& Ramachandran , S. Conceptual framework for performance assessment: Competency, competence and performance in the context of assessments in healthcare - Deciphering the terminology. 2012, 1-9 Early Online Medical Teacher. Doi: 10.3109/0142159X2012.722707.

9. Westera W. Competences in education: a confusion of tongues. Journal of Curric Stud, 2001; 33:75-88.

10. Epstein, RM \& Hundert EM. Defining and assessing professional competence. JAMA 2002; 287:226-235.

11. Hager P, Gonczi A. What is competence? Med Teach 1996; 18:15-18

12. United Nations. International Conference on Population and Development, 994 Summary of the programme of action [http://www. unfpa.org/icpd/summary.cfm]

13. Wall SN, Lee AC, CarloW, Goldenberg R, Niermeyer S, Darmstadt GL. Reducing intrapartum-related neonatal deaths in low-and middle-income countries - what works?. Semin Perinatol 2010, 34:395-407.

14. Lawn JE, Lee ACC, Kinney M, et al. Two million intrapartum-related stillbirths and neonatal deaths: where, why, and what can be done? Int J Gynaecol Obstet. 2009;107 (suppl 1):S5-S18, S19.

15. Mwaniki MK, Atieno M, Lawn JE, Newton CR. Long-term neurodevelopmental outcomes after intrauterine and neonatal insults: a systematic review. Lancet. 2012;379 (9814):445-452).

16. Lawn JE, Blencowe H, Waiswa P, et al ; Lancet Ending Preventable Stillbirths Series study group; Lancet Stillbirth Epidemiology investigator group. Stillbirths: rates, risk factors, and acceleration towards 2030. Lancet.2016;387(10018):587-603. pmid:26794078

17. Msemo G, Massawe A, Mmbando D, Rusibamaylia N, et al. Newborn mortality and fresh Stillbirth rates in Tanzania after helping babies breathe training. Pediatrics 2013; 131: e353-60.

18. Mduma, E, Ersdal H, Svensen E, Kidanto H, Perlman J. Frequent brief on-site stimulation training and reduction in 24 hour neonatal mortality : an educational intervention study. 2015:93:1-7.

https://doi.org/10.1016/j.resuscitation.2015.04.019

19. Kamath-Rayne B.D, Thukral A, Visick M.M, Schoen E et al. Helping Babies Breathe, Second edition: a model for strengthening educational programs to increase global newborn survival. Global Health: Science and Practice. 2018:6(3):538-551. https://doi.org/10.9745/GHSP-D-18-00147.

20. Creswell J. Research design qualitative, quantitative and mixed methods approaches. 2003. $2^{\text {nd }}$ Sage Publications Inc.

21. Morse J.M. Approaches to qualitative-quantitative methodological triangulation. Nursing Research. 1991:40:120123

22. Patton, M.Q. Qualitative evaluation and research methods. 1990. $2^{\text {nd }}$ Newbury Pack. Sage.

23. American Academy of Paediatrics. http://www.helpingbabiesbreathe.org/

24. Castren M. Pre-hospital airway management - time to provide the same standard of care as in the hospital. Editorial. Acta Anaesthesiol Scand. 2008;52:877-8

25. International Liaison Committee On Resuscitation. The international liaison committee on resuscitation (ILCOR) consensus on science with treatment recommendations for pediatric and neonatal patients: neonatal resuscitation. 2006 Pediatrics, 117:e978-e988ILCOR

26. Kirkpatrick D. Great Ideas revisited. Techniques for evaluating training programs: Revisiting Kirkpatrick's four level model. Training Dev 1996;50: 54e9.

27. USAID, National Population Council, Federal Ministry of Health, and Johns Hopkins Bloomberg School of Public Health. 2014. Verbal/Social Autopsy Study: To Improve Estimates of the Causes and Determinants of Neonatal

Page 24/26 
and Child Mortality in Nigeria. Retrieved from healthynewbornnetwork.org/hnn-content/uploads/

28. Essential Newborn care course.

http://www.who.int/maternal_child_adolescent/document/newborncare_course/en

29. Murila F, Obimbo MM, Musoke R. Assessment of knowledge on newborn resuscitation amongst health care providers in Kenya. Pan Afr Health J. 2012.11;78

30. Fullerton JT, Johnson PG, Thompson JB, Vivio D. Quality Considerations in Midwifery Pre-service Education: Exemplars from Africa. Midwifery Journal. Available at https://dx.doi.org/10.1016.j.midw.2010.10.11

31. Ersdal HL, Singhal N. Resuscitation in resource-limited settings. Seminars in Fetal Neonatal Medicine Journal. Elsevier 2013.

32. Flatman D. Best practice in newborn health care, VCO Research Report, 2015. Geneva, World Health Organization.

33. World Health Organiszation. WHO Guideline on basic newborn resuscitation. Geneva. WHO 2011.

34. Uwakah, U, Merritt, S. Providing neonatal resuscitation training in rural Eastern, Nigeria. Training birth attendants to improve neonatal resuscitation knowledge and skill ability. GSTF Journal of Nursing and Health Care (JNHC) 2016: Vol.4 No.1

35. Jukalla AJ, Henley SJ. Readiness for neonatal resuscitation: Measuring knowledge, experience and comfort level. Appl Nurs Res. 2007; 20(2): 78-85

36. Mirkuzie AH, Sisay, MM, Reta, AM, Bedane, MM. Current evidence on emergency obstetric and new born care services in Addis Ababa Ethiopia. BMC Pregnancy and Childbirth 2014, 14:354.Available at https://doi.org/10.1186/1471-2393-14-354

37. Berhe, AK, Tinsae, F, Gebreegziabher, G. Knowledge, the practice of newborn care and associated factors among health care providers in public health facilities of eastern zone, Tigray, Ethiopia. BMC Pediatrics2017 17:157. Available at https://doi.org/10.1186/s12887-017-0915-8

38. Bhurji JK. Determination of the Adherence of Nurses to National Neonatal Resuscitation guildelines at Pumwani Maternity Hospital. MMed Thesis Paediatrics and Child Health, 2011. University of Nairobi.

39. Opiyo N, Were F, Govedi F, Fegan G, Wasunna A, English M. Effect of newborn resuscitation training on health worker practices in Pumwani Hospital, Kenya. PLoS ONE. 2008; 3(2):e1599. Available from: http://www.researchgate.net/publication/5580704/

40. Alwar T.O. Newborn resuscitation: Knowledge and practice among midwives in Keyatta National Hospital Labour ward and Maternity Theatre. MMed Thesis Paediatrics and Child Health, 2010. University of Nairobi.

41. Cadungog-Uy J, Theary C, Ketsana C, Khemarith R, Chanthy T. The Neonatal Resuscitation Skills Training Program in Cambodia. Its impact on the Health Care Professionals' Competency in Newborn Resuscitation.

42. Shikuku DN, Milimo B, Ayebare E, Gisore P, Nalwadda G. Quality of care during Neonatal Resuscitation in Kakamega Country General Hospital, Kenya: A direct observation study. BioMed Research International, Hindawi, Vol 2017. https://doi.org/org/10.1155/2017/2152487

43. Otido S. Adherence to Newborn Resuscitation Guidelines in Garissa Provincial General Hospital. MMed Dissertation, Paediatrics and Child Health, 2013. University of Nairobi.

\section{Figures}




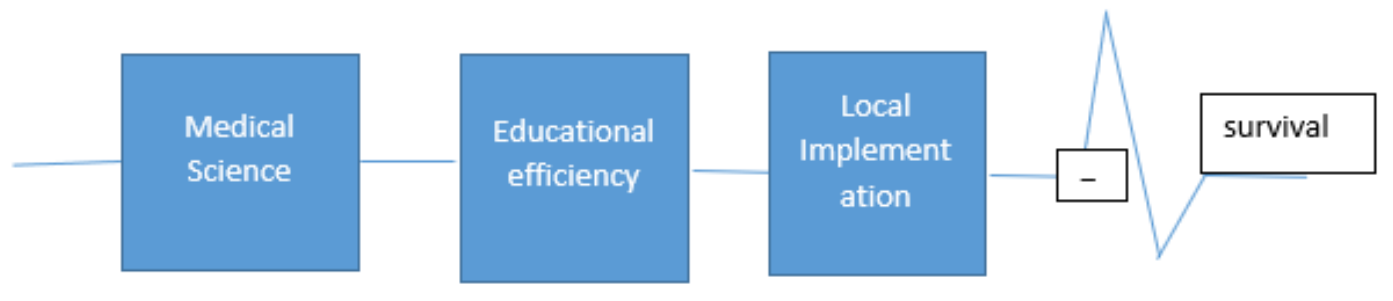

Figure 1

Utsetein formula of survival

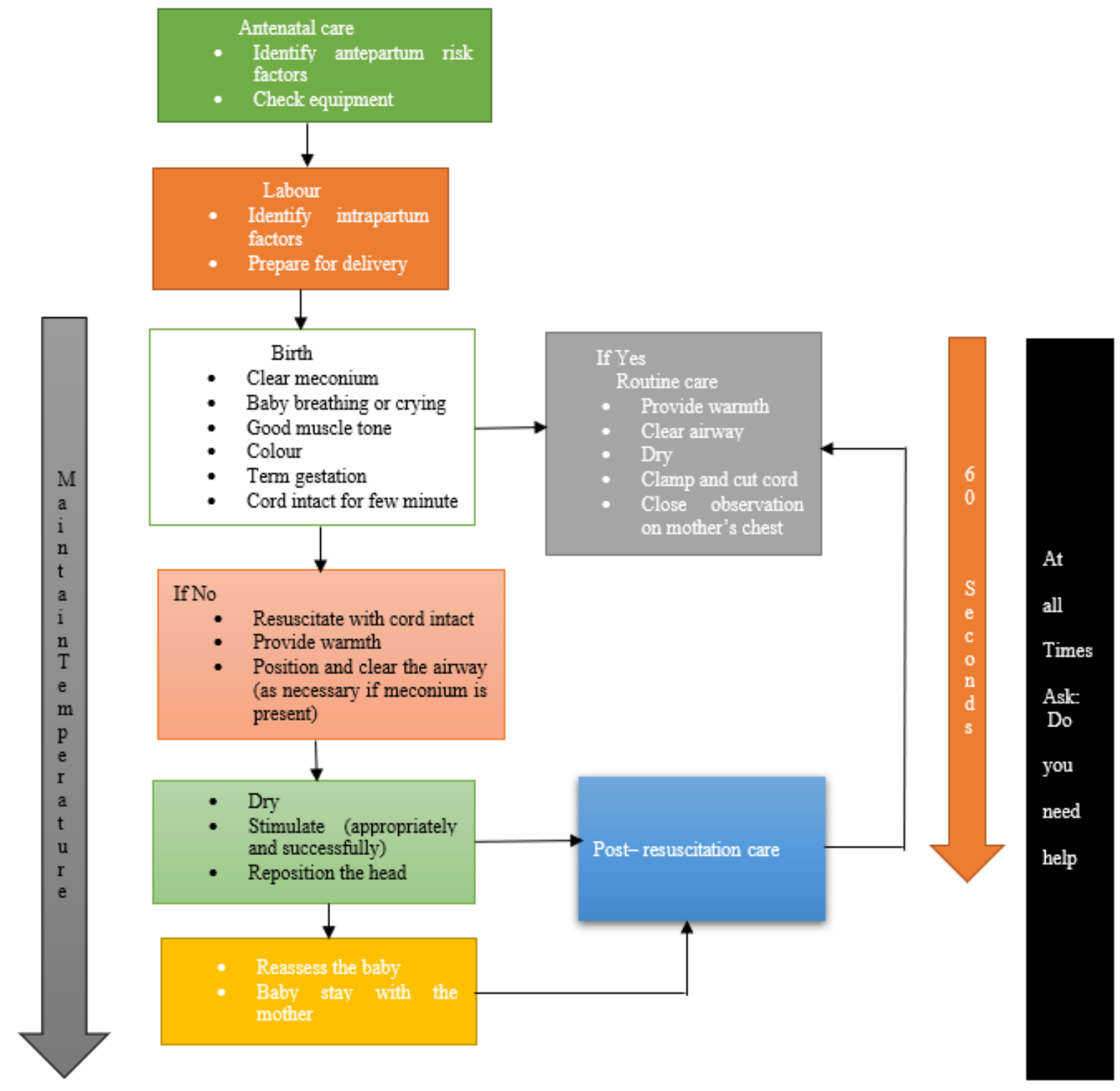

\section{Figure 2}

Refined Neonatal Resuscitation Training Model for Semi-skilled Birth Attendants in Nigeria 